\title{
Developing and implementing systems engineering and project management processes at CSiT - A small Canadian company in public transportation
}

\author{
Claude Y. Laporte \\ École de technologie supérieure \\ Department of Software and IT Engineering \\ 1100 Notre-Dame Street West \\ Montreal, Québec H3C 1K3, Canada, \\ claude.laporte@etsmtl.ca \\ Jamil Menaceur \\ Technical Director, CSiT \\ 3191 Louis A. Amos \\ Lachine, Québec H8S 1C4, Canada \\ jamil.menaceur@csintrans.com \\ www.csit.co
}

\author{
Nicolas Tremblay \\ École de technologie supérieure \\ Department of Software and IT Engineering \\ 1100 Notre-Dame Street West \\ Montreal, Québec H3C 1K3, Canada, \\ nicolas.tremblay.9@ens.etsmtl.ca
}

\author{
Ronald Houde \\ Mannarino Systems \& Software \\ 100 Alexis-Nihon Blvd, Suite 650 \\ Saint-Laurent, Québec H4M 2P2, Canada \\ Ronald.Houde@mss.ca
}

Copyright (C) 2016 by C.Y. Laporte, N. Tremblay, J. Menaceur, D. Poliquin and R. Houde, Permission granted to INCOSE to publish and use.

\begin{abstract}
A project was created to define and implement project management and systems engineering processes at CSinTrans Inc. (CSiT), a Canadian company, founded in 2011. CSiT specializes in the integration of communication and security systems in transit industry such as trains, subways and buses as well as railway stations, subway stations and bus stops. ISO/IEC 29110 standard and guides for systems engineering have been used as the main reference for the development of these processes.

The project's history, purpose and rationale that prompted CSiT to adopt this recently published standard are presented. The implementation of the standard is described. The reflections and decisions made during the implementation are presented. The lessons learned are discussed. Recommendations and advice for organizations wanting to implement ISO/IEC 29110 are described.
\end{abstract}


ISO 29110 has helped raise the maturity of the organization by implementing proven practices and developing consistent work products from one project to another. ISO/IEC 29110 was a good starting point to align processes with specific practices of $\mathrm{CMMI}^{\circledR}$ Maturity Levels 2 and 3. ISO/IEC 29110 has also helped CSiT with developing light processes as well as remaining flexible and quick in its ability to respond to its customers.

\section{Introduction}

CSiT is a Canadian company, established in 2011 in Montréal, providing multi-modal Integrated Communications Systems and information integration for transport. Figure 1 illustrates a system integrated by CSiT.

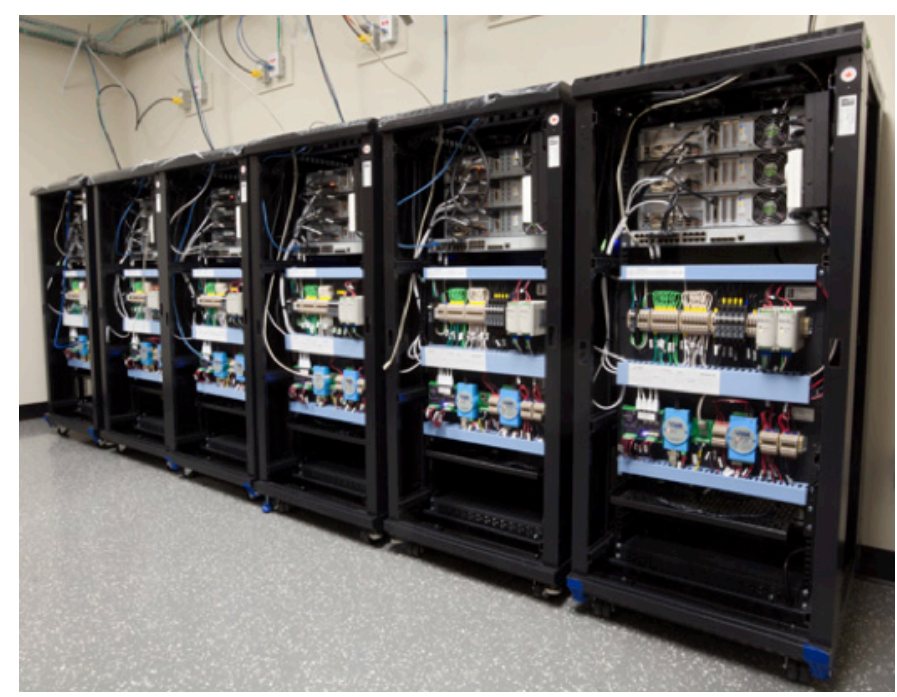

Figure 1. System integrated by CSiT

In transit industry, customers often require a $\mathrm{CMMI}^{\circledR}$ maturity level from companies such as CSiT (SEI 2010). An independent evaluation confirming a CMMI ${ }^{\circledR}$ level 2 increases the opportunity of winning contracts. Similarly, to ensure better work coordination and reduce risks, organizations in this industry prefer working with mature suppliers in order to get timely quality products and within the agreed budget.

\section{ISO/IEC 29110 Standards and Guides}

As defined in ISO/IEC 29110 (ISO 29110 hereon), a Very Small Entity (VSE) is a company, an organization (e.g. government, not-for profit), a department or a project 
having up to 25 people (ISO 2011a) ${ }^{1}$. VSEs can play different roles in systems engineering (SE): either as suppliers or integrators, and sometimes both. Since most large organizations are structured in a way to be more manageable (e.g. project, department), VSEs are present at all stages of a product manufacturing chain.

The SE ISO 29110 have been developed using, as its main framework, ISO/IEC/IEEE 15288 (ISO 2015). With some exceptions, document descriptions are based on ISO/IEC/IEEE 15289 (ISO 2015b). A first four-stage ISO 29110 roadmap has been developed for VSEs that do not develop critical systems: Entry, Basic, Intermediate, Advanced. VSEs targeted by the Entry profile are those working on small projects (e.g., at most six person-months of effort) and for start-ups. The Basic profile describes the development practices of a single application by a single project team. The Intermediate profile is targeted at VSEs developing multiple projects with more than one team. The Advanced profile is targeted at VSEs wishing to sustain and grow as independent competitive businesses.

The systems engineering (SE) Basic profile, as illustrated in figure 2, is composed of two processes: Project Management (PM) and System Definition and Realization (SR). An acquirer provides a SOW as an input to the PM process and receives a product as a result of SR process execution.

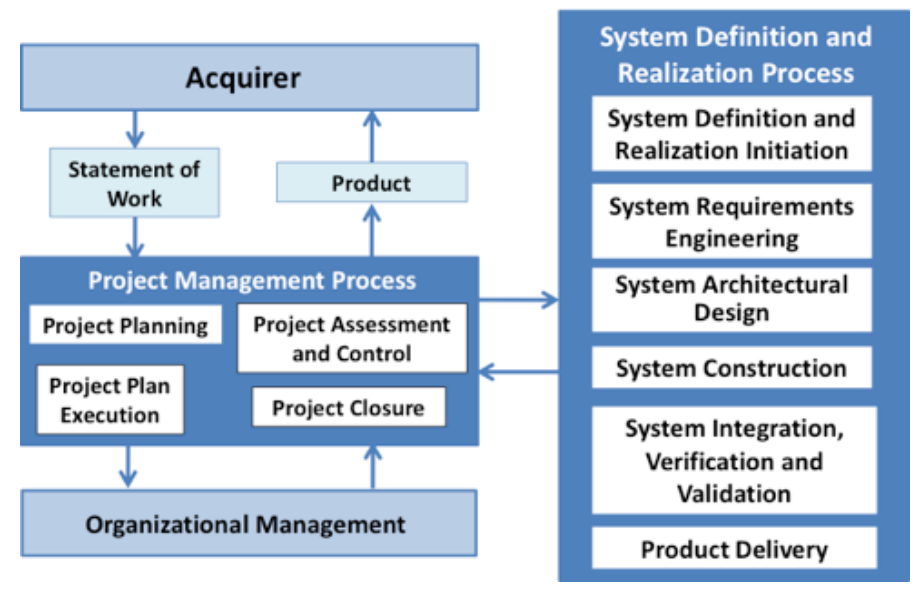

Figure 2. Processes and activities of the systems engineering Basic Profile (Laporte 2014)

The SE ISO 29110 standard and guides are designed to work hand-in-hand with software engineering (SW) ISO 29110. ISO 29110 does not impose a specific life cycle model, therefore leaving VSEs free to choose the model that best suits their needs among the cascade, iterative, incremental, evolutionary and agile models. Similarly, ISO 29110 does not impose a specific method to its users.

\footnotetext{
${ }^{1}$ Readers that want to learn more about ISO/IEC 29110 are invited to read the paper presented at the 2014 Symposium: Laporte, C.Y., Houde, R., Marvin, J., Systems Engineering International Standards and Support Tools for Very Small Enterprises, Presented at the 24th Annual International Symposium of INCOSE (International Council on Systems Engineering), Las Vegas, US, June 30th-July 3, 2014.
} 
So far, the SE Entry profile (ISO 2015a) and the SE Basic profile (ISO 2014) have been published. The SE Intermediate profile development should be completed in 2016 and published in 2017. The SE Advanced profile development should start in 2017. The SE Basic profile guide is available in English, French ${ }^{2}$. The German chapter of INCOSE GfSE (Gesellschaft für Systems Engineering e.V.) ${ }^{3}$ has sponsored the translation of the systems engineering Basic profile. The German standard organization DIN (Deutsches Institut für Normung) ${ }^{4}$ will publish in 2016 the Basic profile in its catalogue. Finally, a translation in Arabic is lead by an engineer of the Canadian department of Defense.

\section{Motivations and objectives of the implementation of ISO 29110 at CSiT}

Shortly after its creation in 2011, CSiT learned that an event in Montréal would be held on the new ISO 29110 management and engineering guide for systems engineering. This standard was seen as a good starting point towards implementing CMMI level 2. Thus, CSiT has undertaken a new project to implement the ISO 29110 standard to guide the project management and system development activities. The Intermediate profile was targeted as it applies to VSEs that conduct several projects simultaneously with more than one team. However, the Basic profile was selected since the Intermediate profile was not published when the project was initiated at CSiT.

\section{Motivations for the implementation of project management and engineering processes}

Several factors prompted CSiT to develop and document their processes. Their first projects were based on employees' experience as well as recognized practices. This approach was effective and agile, but it was not possible to produce consistent deliverables from one project to another and be able to demonstrate that the work could be done over again since these practices were not documented into company's processes. Also, since there were no templates or checklists, project management and product development activities were done rather informally. Finally, considering business and nature of projects of CSiT, customers often require proof demonstrating rigorous work and a level of maturity.

Therefore, the company considered the development and implementation of processes as a need, in other words the situation could become problematic if no action was taken. Specifically, the lack of a CMMI maturity level or compliance with international standards, such as ISO 29110, was not an option. CSiT wanted to ensure the company's growth and show its expertise and organizational maturity to its customers.

\footnotetext{
${ }^{2}$ Available at no cost from ISO: http://standards.iso.org/ittf/PubliclyAvailableStandards/index.html

3 http://www.gfse.de

${ }^{4}$ http://www.din.de/en
} 


\section{Guidance for the implementation project}

To avoid making the process cumbersome and producing too many documents, participants gave themselves 2 sets of guidelines:

1. For processes, the guideline was to add tasks not described in the SE Basic profile only if they bring value to the context and projects of the company or provide an alignment with CMMI level 2.

2. For document templates, the guidelines were:

- Group different documents into one where possible;

- Each template's section must be relevant and applicable. If a section does not provide added value, it should not be included.

\section{Approach to the Implementation of the SE ISO 29110 at CSiT}

The first phase of the improvement project was to determine the set of documents to be produced during a typical project and how they should be organized in the document structure of the company. The five types of documents at the foundation of the company's quality system are illustrated in Figure 3.

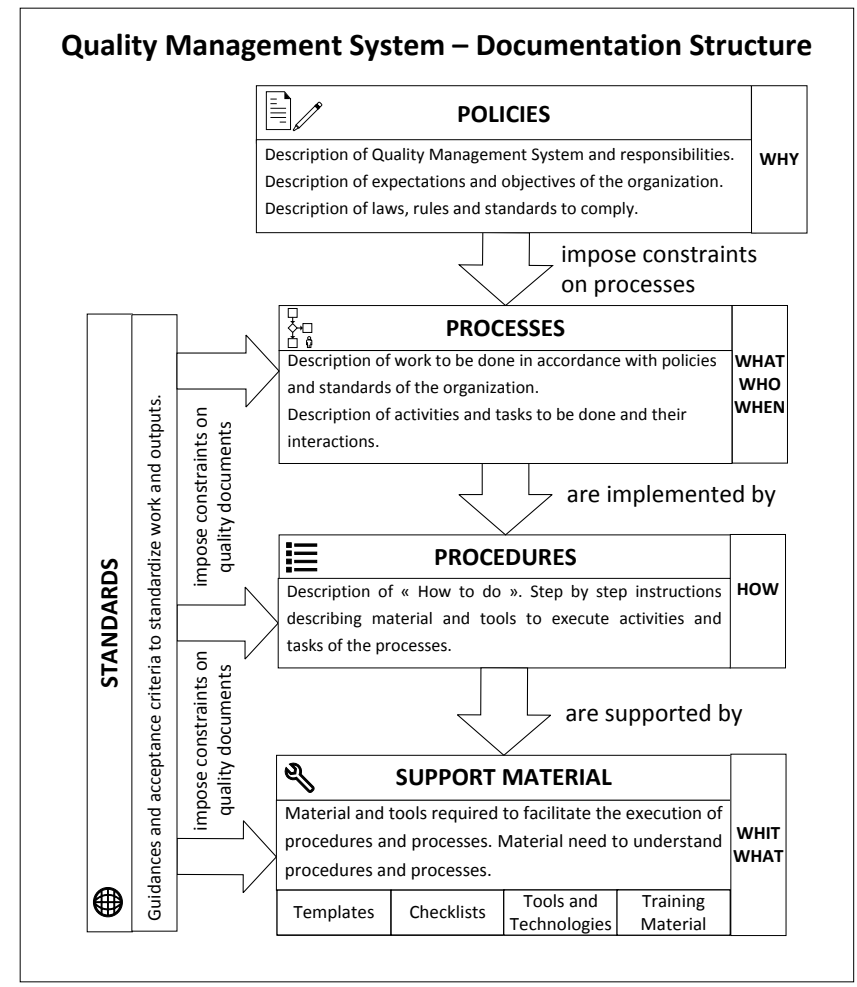

Figure 3. Identification of documents and their relationships 
For the moment, CSiT decided to leave aside the creation of training material because this material can take time to develop and does not really bring value at this time. The company prefers to promote interactive training in person rather than the reading of a document or the viewing of a presentation. Documented processes can be used as training material for new employees as necessary.

\section{Processes and procedures description}

To better respond to different types of projects, CSiT decided to develop three process groups (light, standard, full), each being adapted to meet the attributes of projects such as the size and nature. Table 1 shows the three process groups and the frameworks to be used as reference.

Table 1: Classification of CSiT processes

\begin{tabular}{|l|l|l|l|}
\hline & \multicolumn{1}{|c|}{ Light Process } & \multicolumn{1}{|c|}{ Standard Process } & \multicolumn{1}{c|}{ Full Process } \\
\hline & $\begin{array}{l}\text { Proof of Concept, } \\
\text { Prototype }\end{array}$ & Typical Project & $\begin{array}{l}\text { Project when CMMI } \\
\text { level 2 is required by a } \\
\text { Customer }\end{array}$ \\
$\begin{array}{l}\text { Type of } \\
\text { Project }\end{array}$ & $\begin{array}{l}\text { Concept validation } \\
\text { or Product } \\
\text { Deployment at } \\
\text { Customer Site }\end{array}$ & $\begin{array}{l}\text { Product intended to } \\
\text { be installed at } \\
\text { Customer Site }\end{array}$ & $\begin{array}{l}\text { Product intended to be } \\
\text { installed at Customer } \\
\text { site }\end{array}$ \\
& Small Project & Medium Project & Large Project \\
\hline \multirow{5}{*}{$\begin{array}{l}\text { Framework } \\
\text { to be used }\end{array}$} & $\begin{array}{l}\text { ISO/IEC TR } \\
\text { 29110-5-6-1 Entry } \\
\text { Profile } \\
+\end{array}$ & $\begin{array}{l}\text { ISO/IEC TR 29110- } \\
5-6-2 \text { Basic Profile } \\
+\end{array}$ & CMMI (Level 2) \\
& $\begin{array}{l}\text { CMMI - Supplier } \\
\text { CMgreement }\end{array}$ & \\
& $\begin{array}{l}\text { Agreement } \\
\text { Management }\end{array}$ & Management & \\
\hline
\end{tabular}

\section{Using the management and engineering guide of ISO 29110}

To document CSiT processes, the management and engineering guide of ISO 29110 SE Basic profile was used as the main reference (ISO 2014). The software engineering (SW) management and engineering guide of ISO 29110 Basic profile (ISO 2011b) was also used as a reference to complement the SE guide. The SW guide was used to document processes involving the development of SW elements of a system.

\section{Using deployment packages}

Members of the INCOSE VSE working group ${ }^{5}$ have created Deployment Packages (DPs) (Laporte 2016) to facilitate the adoption and implementation of ISO 29110. These free

${ }^{5}$ http://www.incose.org/ChaptersGroups/WorkingGroups 
resources, available on Internet, have been used to support the documentation of CSiT processes. Figure 4 shows the SE set of DPs.

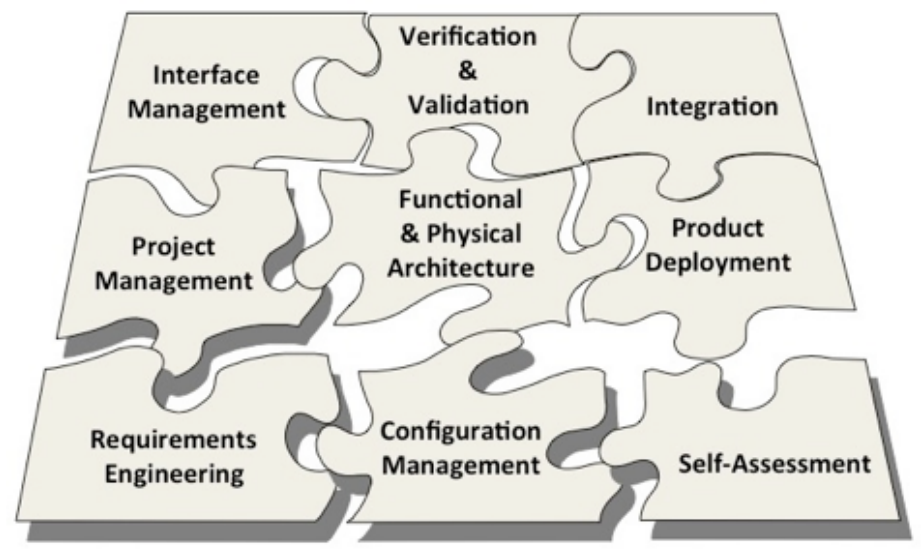

Figure 4. Deployment packages to support the SE Basic Profile

Since the SE DPs were in development during this implementation project, the SW DPs, developed by members of the ISO working group responsible for ISO 29110, were used.

\section{Process documentation}

For the description of processes, CSiT decided to break down processes into activities and tasks. There are two reasons for this representation. First, this representation is simple and it is commonly used in industry and literature. Second, it is consistent with ISO 29110, which is structured the same way.

\section{Graphical and textual documentation of processes}

It was decided that documentation of CSiT processes would consist of two parts: a graphical part and a textual part. Each of these parts has different but complementary goals. The graphical part is primarily targeted at "experts", while the textual part is targeted mainly at "beginners" (e.g. a new employee) or an intermediate user (e.g. an employee who has participated to an engineering project) (Laporte and April 2011).

The ETVX notation (i.e. Entry-Task-Verification-eXit) was developed in the 80s by IBM (Radice and Roth 1985). Given its simplicity of use, it has been adopted by many organizations such as NASA. The textual part is a detailed description of activities, tasks and interactions between the activities of a process. The textual part describes the tasks, i.e. what to do, and the roles associated with each task. The template for the textual description of the activities and tasks is shown in Figure 5. 


\begin{tabular}{|c|c|}
\hline Name of Ac & tivity \\
\hline Objective: & \\
\hline Rationale: & \\
\hline Roles: & \\
\hline Entry Criteria & • \\
\hline Inputs & \\
\hline Outputs & \\
\hline Exit Criteria & • \\
\hline Metrics & \\
\hline Tasks & 1. Task 1 \\
\hline & 2. Task 2 \\
\hline & 3. Task 3 \\
\hline & 4. Task 4 \\
\hline
\end{tabular}

Figure 5. Template for the textual part of an activity

The format used to describe the activities is the notation used in the DPs of ISO 29110. Some adjustments were made to add a few attributes, such as metrics to collect, entry and exit criteria.

\section{Techniques Used to Help Defining and Implementing ISO 29110}

The Basic profile presents the project management and development processes using a waterfall lifecycle to simplify its understanding. However, the ISO 29110 guide indicates that it does not require the waterfall lifecycle, leaving VSEs to use the lifecycle that best suits their needs. Thus, CSiT decided to develop their own lifecycle models: a project lifecycle and a system development lifecycle.

The definition of these lifecycle models have facilitated the description of the processes because they provided a clear understanding of when the processes need to be executed. In addition, the lifecycles have shown the importance of some processes that are not mentioned in the standard, but that must be used during the execution of projects. For example, it is possible that the company has to perform validation tests on the customer' site, to get the final acceptance of the system. For CSiT, this type of work is essential and was documented as a separate process.

\section{Identification of verification, validation and acceptance activities applicable to work products}

An important decision, made during the development of CSiT's processes, was to determine the types of peer review activities to be applied to the various work products of a project. ISO 29110 states that verifications of work products must be made, but without specifying the type. This leaves VSEs free to decide what best verification method applies to their context. For each deliverable, a decision was made for the adequacy or 
the need to perform at least one type of peer review. Four types of reviews were identified: personal review, desk-check, walkthrough and inspection.

\section{Acceptance of deliverables}

ISO 29110 defines the roles needed to produce and review the project deliverables (documentation and product components), but it does not define the roles of the people who must approve and/or sign deliverables before they are sent to a customer, a supplier or other external stakeholders. CSiT developed a table indicating, for each deliverable, whether or not an internal approval is needed, whether or not it should sent to the customer and whether or not a customer approval is required.

\section{Selection of measures}

The management and engineering guide lists the tasks associated to the collection and use of measures (e.g. resource, cost, time). The Basic profile does not detail how to collect and analyze the measures.

The selection of measures were based on two principles: 1) a measure must meet a company's needs for information and, 2) a measure must be easy to collect and analyze. A subset of the measures selected is described in Table 2.

Table 2: Subset of process and product measures

\begin{tabular}{|c|c|c|}
\hline Measure ID & Measures & Reasons \\
\hline MET-01 & $\begin{array}{l}\text { Number of errors detected by document } \\
\text { type and by phase of the development cycle }\end{array}$ & $\begin{array}{l}\text { To know the overall quality of } \\
\text { each work product }\end{array}$ \\
\hline MET-02 & $\begin{array}{l}\text { Number of hours worked for each phase of } \\
\text { the system development cycle }\end{array}$ & \multirow{3}{*}{$\begin{array}{l}\text { To be able to use the performance } \\
\text { of past projects to estimate new } \\
\text { projects }\end{array}$} \\
\hline MET-03 & The cost of each project & \\
\hline MET-04 & $\begin{array}{l}\text { The attributes of each project: } \\
\text { Number of change requests; } \\
\text { Level of risk; } \\
\text { Predominance hardware/software. }\end{array}$ & \\
\hline MET-05 & $\begin{array}{l}\text { Distribution of effort related to the } \\
\text { production, review and correction of } \\
\text { deliverables }\end{array}$ & $\begin{array}{l}\text { To be able to analyze the } \\
\text { efficiency of processes on } \\
\text { product quality }\end{array}$ \\
\hline MET-06 & $\begin{array}{l}\text { Resources spent versus those that were } \\
\text { planned in the project plan }\end{array}$ & $\begin{array}{l}\text { To be able to analyze if the } \\
\text { project is successful, to identify } \\
\text { gaps and take the necessary } \\
\text { remedial action }\end{array}$ \\
\hline
\end{tabular}


An electronic time sheet has been established to record the number of hours worked on each work product of a project. The timesheet allows to classify efforts in 3 categories: efforts spent on the initial production of a work product, efforts spent on reviewing it and efforts spent on correcting identified defects. This data provides valuable information when improving a process.

\section{Traceability between work products}

ISO 29110 includes tasks to trace information between work products. Based on these tasks, a graphical representation was set up to show how traceability is generated between the various work products of CSiT. Only a few adjustments were made to the tasks of ISO 29110 to better reflect the context of CSiT:

- Traceability between unit tests and detailed design elements has been added.

- Traceability between the detailed design and architecture document has been defined as optional. This customization does not cause any problem for compliance with the standard since this type of traceability is not mentioned;

- Names of ISO 29110 documents have been adapted to fit documents' titles used by CSiT.

\section{Definition of a Supplier Management Process}

Since CSiT is a system integrator, the company uses suppliers for the purchase and development of components that will be used in a product. Therefore, it was imperative for CSiT to establish a supplier management process that defines how to work with them and to reduce project risks.

The SE Basic profile has only a few tasks about the 'make or buy' decisions and followup actions (e.g. document, review and issue a purchase order). Unfortunately, the current version of the SE Basic profile does not describe a supplier management process. This process is covered in the system and the software Intermediate profiles (ISO 2016a, ISO 2016b). The $\mathrm{CMMI}^{\circledR}$ for Development has been consulted, as well as ISO/IEC/IEEE 15288 (ISO 2015a), the INCOSE Handbook (INCOSE 2015) and the PMBOK ${ }^{\circledR}$ Guide (PMI 2013).

\section{Coverage between Frameworks}

As mentioned earlier, the project goal was to implement ISO 29110 and to complement it with CMMI level 2 requirements. In order to determine the achievement of this objective, an analysis of the coverage of CSiT processes was performed. This analysis was done in two stages. First, the correspondences between the CSiT processes with ISO 29110 have been defined. Then, connections between the processes of CSiT and those of CMMI were defined.

An analysis confirmed that the processes of CSiT fully cover the objectives and tasks of the processes defined in the Basic profile. During this analysis, mappings and tailoring have been documented. This documentation also explains the tailoring decisions of CSiT. 
The mapping of CSiT processes with CMMI-DEV level 2 process areas revealed that many of the generic and specific practices are covered. However, some practices still remain to be implemented or improved.

\section{Implementation of ISO 29110 and Self-Assessment and Audit}

In 2012, CSiT started the development of a product suite called 'TRANSIS'. TRANSIS is a multimodal information data integration system with interactive extensions for operators and users of public transport. This project was intended to apply the processes and adjust them if necessary, ensuring a gradual adoption of the new work methods.

CSiT has tested the degree of implementation of its processes in the TRANSIS project. To do this, the self-assessment score sheet of ISO 29110 (Laporte 2015c) was used. This score sheet was used to indicate the activities, tasks and documents produced during a project and determine the level of compliance with the standard. At the middle of the project, an assessment showed that most of the project management and system development tasks have been executed. The tasks that have not yet been covered will be executed in subsequent phases of the TRANSIS project.

Recently, the systems engineering Basic Profile of the ISO 29110 has been successfully audited by a third-party audit team composed of 2 independent auditors. One member of the audit team was a systems engineering domain expert.

\section{Lessons Learned}

The initial approach at CSiT was to develop one process at a time, documenting it graphically and then textually. The problem is that by doing so, the interactions between processes were not considered. Therefore, when a new process was developed, the team could discover that the already described processes should be modified to better reflect this new process. At some point of the improvement project, it was decided to document all processes in a graphical representation before documenting the textual version of each process. This approach had two advantages. First, it helped to get the big picture of the processes and their interactions. Also, it enabled the team to use and apply these processes faster in a pilot project and determine whether the activities and tasks defined in the process were relevant and if some were missing. The textual description of the process was resumed as soon as the interactions between processes were better defined and the description of activities and tasks of the process was more stable.

It was also learned that processes could be represented graphically in a simple way. Although there are many specialized tools on the market and many process modeling standards, these tools were too "heavy" for the needs of a VSE. A tool such as the Microsoft Visio tool was sufficient to document processes as a set of flowcharts.

It was found that even if two terms that are similar could be considered as synonyms, it could create some confusion. For example, the terms "architecture" and "design" are similar to the extent that they represent how a system is designed or is a solution to a 
given problem. Some people might interchange the words, but fundamentally each of them represents a different concept. The architecture is the high-level structure of a system, its elements and their relationships while the design describes, amongst others, the detailed implementation-level physical structure, behavior, temporal relationships of the elements of a system. A control of the terminology used in the business domain of an organization and by its customers is essential. A document standardizing the terms used should be developed and maintained.

\section{Recommendations}

Resulting from the development and implementation of project management and system engineering processes at CSiT, a set of recommendations was developed to help VSEs in implementing ISO 29110. Here is a list of few of them.

\section{Define the vision and objectives of a process improvement project}

Any process improvement project should begin with a clear definition of the business motivations and objectives of the initiative. This will help define the scope of the improvement project.

It is important to ensure that the new or improved processes will meet the needs of the VSE to ensure that they are not implemented due to a 'misconnect' with the day-to-day activities of the VSE. Also, with clear and ideally quantified objectives, it will be possible to determine whether the expected results have been met.

\section{Choose a framework that meets the needs of the VSE}

VSE should seriously consider the option of ISO 29110 , because it is a simple standard is much less bulky and demanding than other standards. It covers project management and system and software development and sticks to the basics. Certificate of conformity and assessment certificates have been issued to VSEs that develop products with ISO 29110. Similar schemes should be available soon for VSEs developing systems. Also, VSEs should take the time to choose the profile that best meets their organization. A freely available ISO 29110 management and engineering guide and a set of deployment packages facilitate the implementation of the ISO 29110 standard.

\section{Adapt the framework selected to the context of the VSE}

Regardless of the framework selected, it is important to adapt it to the context of the VSE. Frameworks, such as ISO 29110 or CMMI are, on purpose generic such that they can apply to a wide range of organizations. It is important to do some adaptations, while remaining consistent with the selected framework.

For example, it is important to adapt the terminology such as the name of a process, the title of documents and the names of roles to fit to the context of the VSE. Also, it is important to define a set of processes that matches the needs of the VSE and the lifecycle of projects. 


\section{Define the structure of the project directories or project repositories}

All deliverables and internal work products must be stored in a file structure and/or a configuration management tool. A VSE should adopt a uniform directory structure from one project to another. In this way, it is easy to navigate and to work more efficiently. There are many ways to organize project directories; each VSE should define a structure that meets its needs.

\section{Define a generic template for documents}

A VSE that wishes to establish documented processes and organize its work methods consistently from project to project should consider the introduction of a generic document template that can be used for all (or most) project documents. A template describing a cover page, a table of contents, a table of changes and layout avoid reinventing the wheel and having non-homogeneous materials. Having a generic template saves time when creating a template for a particular document or a project having specific needs.

\section{Group documents as required}

Grouping documents minimizes the number of manipulations (e.g. drafting, reviewing, approving) and the number of documents managed and stored. For example, the risk management plan could be included in the project plan instead of a separate document unless a customer wants separate documents. When in doubt, it is suggested to group documents for purposes of simplicity and separate them later as needed.

\section{Define the verification, validation and acceptance of documents and product elements}

A good way to facilitate the documentation process is to define the verification, validation and acceptance criteria that applies to each output and each deliverable. Once completed, this table enables a clear picture of the quality control and acceptance activities that must be performed during a project.

\section{Define measures to collect}

It is normal for a VSE to have expectations on performance and the quality of project work products. To determine if these expectations are met, a VSE should monitor the progress of its projects and collect the necessary measures. These measures can be simple such as budget spent, the number of hours spent, the number of days late or ahead of the original schedule, the number of defects found in a document and in the developed product, the number of tasks performed on the number total of tasks defined in the project plan, the risk level of the project.

\section{Conduct a Pilot Project}

New processes should always be used in a pilot project to test their effectiveness, to detect omissions, contradictions, errors and ambiguities. This small-scale deployment 
allows a VSE to make adjustments smoothly. Once developed, the new processes can be deployed across the VSE successfully.

\section{Conclusion}

This article has presented the development and the implementation of management and engineering processes at CSiT using the recently published ISO/IEC 29110 for systems engineering. ISO/IEC 29110 has greatly facilitated this work because it describes in details the processes that must be documented and implemented.

It was easy for CSiT to adapt ISO/IEC 29110 to its business context. ISO/IEC 29110 helped implementing lightweight processes. This way CSiT remains a flexible organization.

ISO/IEC 29110 helped raise the organization's maturity by using industry-recognized practices that are consistent from project to project. It can be said that the standard is simple to understand and use. It is also a good starting point for a VSE that wants to cover CMMI-DEV Level 2 and 3 practices. It enables VSEs, such as CSiT, to become more mature more rapidly by adopting systematic, disciplined and quantifiable methods of work, which are typical of engineering environments.

\section{Additional Information}

The following Web site provides more information, as well as articles by WG24 members and deployment packages for system and software engineering in English, French and Spanish:

http://profs.logti.etsmtl.ca/claporte/English/VSE/index.html

\section{References}

DIN, ISO/IEC TR 29110-5-6-2:2014 System und Software-Engineering - LifecycleProfile für Kleinstunternehmen (VSEs) - Teil 5-6-2: Management und Engineering Leitfaden: Generische Profilgruppe: Basis profile, Deutsches Institut für Normung. Available at: http://www.din.de/en

INCOSE, Systems Engineering Handbook: A Guide for System Life Cycle Processes and Activities, 4th Edition, ISBN: 978-1-118-99940-0, 304 pages, 2015

ISO, ISO/IEC TR 29110-1: 2011 - Systems and software engineering -Lifecycle profiles for Very Small Entities (VSES) - Part 1: Overview, International Organization for Standardization, Geneva, 2011. Available at no cost from ISO: http://standards.iso.org/ittf/PubliclyAvailableStandards/index.html 
ISO, ISO/IEC TR 29110-5-1-2: 2011 - Software Engineering - Lifecycle profiles for Very Small Entities (VSES) - Part 5-1-2: Management and engineering guide: Generic profile group: Basic profile, International Organization Standardization: Geneva, Switzerland, 2011. Available at no cost from ISO: http://standards.iso.org/ittf/PubliclyAvailableStandards/index.html

ISO, ISO/IEC TR 29110-5-6-2:2014 - Systems and software engineering - Lifecycle profiles for Very Small Entities (VSES) - Part 5-6-2: Systems engineering Management and engineering guide: Generic profile group: Basic Profile, International Organization for Standardization, Geneva, Switzerland, 2014. Available at no cost from ISO: http://standards.iso.org/ittf/PubliclyAvailableStandards/index.html

ISO, ISO/IEC TR 29110-5-6-2:2014 - Ingénierie des systèmes et du logiciel - Profils de cycle de vie pour les très petits organismes (TPO) - Partie 5-6-2: Ingénierie des systèmes - Guide de gestion et d'ingénierie: Groupe de profils génériques: Profil basique. Disponible gratuitement de l'ISO:

http://standards.iso.org/ittf/PubliclyAvailableStandards/index.html

ISO, ISO/IEC/IEEE 15288: 2015. Systems and software engineering: system life cycle processes, 2nd ed. Geneva: International Organization for Standardization, 2015.

ISO, ISO/IEC/IEEE 15289:2015, Systems and software engineering - Content of systems and software life cycle process information products (Documentation), International Organization for Standardization/International Electrotechnical Commission: Geneva, Switzerland.

ISO, ISO/IEC TR 29110-5-6-1:2015 - Systems and software engineering - Lifecycle profiles for Very Small Entities (VSES) - Part 5-6-1: Systems engineering Management and engineering guide: Generic profile group: Entry Profile, International Organization for Standardization, Geneva, Switzerland, 2015. Available at no cost from ISO: http://standards.iso.org/ittf/PubliclyAvailableStandards/index.html

ISO, ISO/IEC JCT1/SC7 Working Group 24 Deployment Packages repository, [online] available from: http://profs.logti.etsmtl.ca/claporte/English/VSE/index.html

ISO, ISO/IEC PDTR 29110-5-1-3 - Systems and software engineering - Lifecycle profiles for Very Small Entities (VSE) - Part 5-1-3: Software engineering Management and engineering guide: Generic profile group - Intermediate profile. International Organization for Standardization, Geneva, Switzerland, 2016.

ISO, ISO/IEC PDTR 29110-5-6-3 - Systems and software engineering - Lifecycle profiles for Very Small Entities (VSE) - Part 5-6-3: Systems engineering Management and engineering guide: Generic profile group - Intermediate profile. International Organization for Standardization, Geneva, Switzerland, 2016. 
Laporte, C.Y., April, A., 2011. Assurance qualité logicielle, volume 2, Processus de support. Paris: Hermes, 2011 (in French). Available at: http://www.lavoisier.fr/livre/h3222.html

Laporte, C.Y., Fanmuy, G., Ptack, K., 2012. The Development of Systems Engineering International Standards and Support Tools for Very Small Enterprises, 22nd Annual International Symposium of the International Council on Systems Engineering, Rome, July 9-12, 2012. Available at: http://www.etsmtl.ca/Professeurs/claporte/documents/publications/LAPORTE INCOSE 2012.pdf

Laporte, C.Y., Houde, R., Marvin, J., 2014. Systems Engineering International Standards and Support Tools for Very Small Enterprises, Presented at the 24th Annual International Symposium of INCOSE (International Council on Systems Engineering), Las Vegas, US, June 30th-July 3, 2014. Available at: http://www.etsmtl.ca/Professeurs/claporte/documents/publications/INCOSE2014.pdf

Laporte, C.Y., Chevalier, F., 2015. An Innovative Approach to the Development of Project Management Processes for Small-scale Projects in a large Engineering Company, 25th Annual International Symposium of INCOSE Available at: http://editionweb.etsmtl.ca/Professeurs/claporte/Publications/INCOSE-2015 Tetra Tech.pdf

Laporte, C.Y., Houde, R., 2015. Open Source Systems Engineering Guides, Deployment Packages and Support Tools for Very Small Enterprises - A Case Study, 25th Annual International Symposium of INCOSE (International Council on Systems Engineering), Seattle, US, July 13-16, 2015. Available at: http://editionweb.etsmtl.ca/Professeurs/claporte/Publications/INCOSE201529110 Open-Source.pdf

Laporte, 2016. ISO/IEC 29110 Public site, [online] available from: http://profs.logti.etsmtl.ca/claporte/English/VSE/index.html

PMI, Project Management Institute, 2013. Project Management Knowledge Corpus Guide $\left(\right.$ PMBOK $^{\circledR}$ Guide), fifth edition. Newtown Square, Pa.: Project Management Institute, 2013.

Radice, R.A., Roth, N.K., 1985. A Programming Process Architecture. IBM Systems Journal, 24(2), p. 79-90.

SEI, Software Engineering Institute, 2010. CMMI for Development, Version 1.3, Pittsburgh, PA: Carnegie Mellon University, CMU/SEI-2010-TR-033, 2010. 


\section{Biography}

Dr. Claude Y. Laporte has been a professor since 2000 at the École de technologie supérieure (ÉTS), a 10,000-student engineering school, where he teaches software engineering. His research interests include software process improvement in small and very small enterprises, as well as software quality assurance. He has worked in defense and transportation enterprises for over 20 years. He received a Master's degree in Physics from the Université de Montréal, a Master's degree in Applied Sciences from the École Polytechnique de Montréal and a $\mathrm{Ph} . \mathrm{D}$. from the Université de Bretagne Occidentale (France). He was awarded an honorary doctorate by the Universidad de San Martin de Porres (Peru) in 2013. He is the Editor of ISO/IEC JTC1 SC7 Working Group 24, tasked to develop ISO/IEC 29110 life cycle standards and guides for Very Small Entities. He is the Cochair of the INCOSE Systems Engineering for Very Small Entities WG. He is a member of INCOSE, IEEE, PMI and a member of the professional association of engineers of the Province of Québec. He is the co-author of two French books on software quality assurance published in 2011 by Hermes Science-Lavoisier and one English textbook, on the same topic, to be published by John Wiley and Sons in 2016.

Web site address: http://profs.etsmtl.ca/claporte/English/index.html

Nicolas Tremblay has guided the implementation of ISO/IEC 29110 at CSiT. His project management and process development skills as well as its knowledge of CMMI and ISO environments have been important resources for the execution of the project. He holds a bachelor's degree in software engineering and a Master's degree in Project Management from the École de technologie supérieure. He has several years of experience in software and system engineering. He has worked in medical and aerospace industry, in small and large organizations. He has contributed to the review of the management and engineering guide of ISO/IEC 29110 and the development of support tools including the deployment packages. He is a member of the professional association of engineers of the Province of Québec (Ordre des ingénieurs du Québec) and of Project Management Institute (PMI).

Jamil MENACEUR is technical director at CSiT, a Montreal company specializing in system integration and software design for Communications and Security systems in transit industry. He has over 30 years experience in electronic design, software and mechanics. Fifteen years ago, he seized the opportunity to combine his knowledge to become a system specialist. He worked for Wang, IBM and ALSTOM without forgetting some start-up companies such as Dip Systemes (Paris), ParcoFlex (Montreal), Micral (Algiers) and General

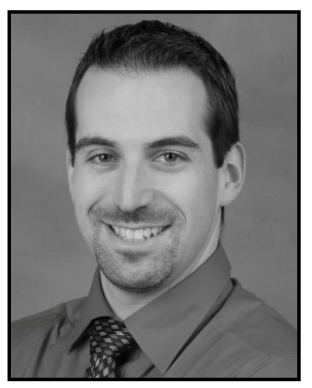
Engineering (Constantine). He holds a degree in engineering from the University Mentouri, Constantine. 
Denis Poliquin is president at CSiT, a Montreal company specializing in system integration and software design for Communications and Security systems in transit industry. His experience includes responsibilities related to systems engineering, marketing, management of marketing, marketing on a global scale as well as general management. He spent over 25 years in the information technology industry focused on large system integration projects. He is a member of the Professional Engineers of Ontario for over 20 years.

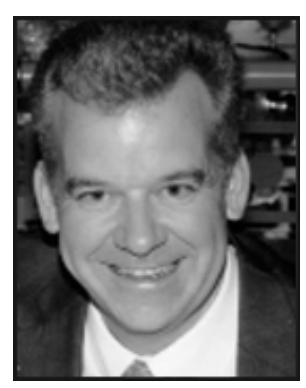

Ronald Houde is a Senior Systems Engineering Specialist with Mannarino Systems \& Software and a delegate of Canada on the ISO JTC1/SC7 Working Group 24. He has over 30 years of experience in government and commercial safety- and mission-critical software and systems engineering. Employers and customers have included world leaders such as Esterline/CMC Electronics, Lockheed Martin, Bombardier Aerospace, CAE, BPR Énergie, Hydro-Québec, the Canadian Department of National Defence and the U.S. Army. His main areas of employment have been in the design, development,

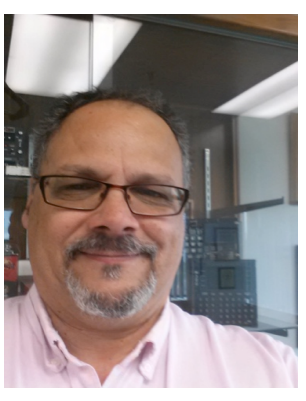
integration and installation of safety-critical software systems and programmable electronic devices. His clients in both industry and government benefit from his skills in training and mentoring, complex problem analysis and solving, and communication. $\mathrm{He}$ has also been involved in technical training and university and continuing education programs since the early 1990s. He is experienced in the conduct, management and continuous process improvement of software and systems engineering activities covering the entire life-cycle of operational, mission support and safety-critical software systems. $\mathrm{He}$ is an experienced instructor to technical military and civilian audiences, having developed and taught numerous Avionics, Avionics Databus and Requirements Engineering workshops.

LinkedIn profile: https://ca.linkedin.com/pub/ronald-houde/7/597/989 